\title{
Effect of Tele-nursing Education Program on Nurses' Compliance with Standard Precautions during COVID- 19 Pandemic
}

\author{
Shimaa Mohamed Abdou Rizk ${ }^{1}$ \& Bahia Galal Siam ${ }^{2}$ \\ 1. Lecturer of Medical-Surgical Nursing, Faculty of Nursing, Mansoura University, Egypt. \\ 2. Assistant Professor of Medical-Surgical Nursing, Faculty of Nursing, Port Said University, Egypt.
}

\begin{abstract}
:
Coronavirus disease (COVID-19) is a great global public health concern, caused by SARS-COV2 and represents the causative agent of a potentially fatal disease. Aim: evaluate the effect of tele-nursing education program on nurses' compliance with standard precautions during COVID-19 pandemic. A quasi-experimental research design was used. Setting: The study conducted at Specialized Medical Hospital, Mansoura, Egypt. Sample: 218 nurses transversely various clinical units of the hospital. Two tools were used in data collection; a structured interviewing questionnaire, and the compliance with standard precautions scale (CSPS). Results revealed that there was a highly statistically significant difference in all items of compliance with standard precautions scale between pretest and posttest with $\mathrm{p}$ value $<0.001$ and a highly significant statistical difference in mean scores of compliance standards precautions scale between the pre \& post-test, with $\mathrm{p}$ value $<0.001$. Conclusion: Application of the tele-nursing education program had a positive effect on improving the CSPS of the studied nurses as the tele-nursing appears to be a new opportunity in the COVID-19 Pandemic disaster to lessen hazard of infection. Recommendations: Written universal precautions guidelines for infection control should be available and updated periodically
\end{abstract}

\section{Keywords: Tele-nursing Education, Compliance, Standard Precautions \& COVID-19 pandemic}

\section{Introduction}

The 21 st century has confronted one of its greatest challenges. The emergence and logarithmic rise of developing illnesses have darkened the long run of communicable infection due to drug resistance, genetic mutation and contagion (Purabdollah, \& Ghasempour, 2020). Pandemics and scourges are community wellbeing disasters that able to cause considerable mortalities and socio-economic disruption. Coronaviruses are a generous collection of viruses that are relatively shared through the society (Wang, et al., 2020). There was increasing outbreaks of contagious disease during latest years, such Severe Acute Respiratory Syndrome. Finally, novel Corona Virus Infection 2019 (COVID-19) which found in December 2019 in Wuhan, China, which has created a necessary need for extra front line direct-care nurses (Jin, et al., 2020).

COVID-19 symbolizes the causative agent of a potentially lethal disease that is of huge international community health concern (Said, et al., 2020; Rothan \& Byrareddy 2020). Among the human respiratory system infections is Coronavirus, named 2019-nCoV by the WHO and SARS-CoV-2 by the International Committee on Taxonomy of Viruses, this virus is a new human-infecting Beta coronavirus that, relies on its genetic proximity to 2 bat-derived SARS like coronaviruses, likely created in chrysanthemum bats (Del \& Malani, 2020). According to the WHO, Later 31 December 2019 and as of 18 July 2020, entire cases of COVID-19 in harmony with the applied case definitions and testing strategies in the influenced nations have been registered, are 14,044,869 cases including 597,148 deaths. In Africa: 683,966 cases; the five countries reporting greatest cases are South Africa $(337,594)$, Egypt $(86,474)$, Nigeria $(35,454)$, Ghana $(26,572)$ and Algeria $(21,948)$ (WHO, 2020). Egypt is an African country found on the northeast corner of the African landmass with an area of 1,010,408 $\mathrm{km} 2$, and population of more than 100 million. All flights from China to Egypt was stopped on 26 January, 2020. The first case of COVID-19 was discovered in Egypt on 14 February, 2020. The second case was authoritatively declared on 1 March 2020. The Egyptian government has compelled different methods of lockdowns such as locking all universities, schools, and mosques. Healthcare professionals are at a significant risk to have COVID19 infection. Egyptian hospitals have been prepared to face the pandemic; standard precautions have been followed. (Saba \& Elsheikh, 2020).

According to WHO, (2020), COVID-19 virus spread throughout respiratory droplets and contact routes. Droplet transmission appears when a person is in adjacent contact (within $1 \mathrm{~m}$ ) with someone who has respiratory symptoms (e.g. coughing or sneezing,) and is consequently in danger of having his/her mucosae (mouth and nose) or conjunctiva visible to potentially infective respiratory droplets. 
Consequently, transmission of the COVID-19 virus increased by close contact with infected persons and by indirect contact with shells in the contaminated objects utilized by the infected people.

Standard Precautions are vital for disease control for the management of entire patients independent of diagnosis. It states all approaches, strategies, and activities that point to anticipate or decrease the threat of the spread of infectious illness at health care foundations (Donati, et al., 2019). Standard safety measures involve hand hygiene (schedule hand washing, hand antisepsis, surgical hand scrub, personal protective equipment (capes, gowns, masks, aprons, drapes, closed boots or shoes, goggles or glasses, sterile drapes), avoidance of needle stick or sharp injury, waste management, instrument preparing (disinfecting, cleaning, sterilization), preparing linen, housekeeping, and clinical research facility administrations (WHO, 2020). The WHO reports that technology has an expanding role in both education and practice of the nursing workforce. Tele-nursing is one of the greatest significant technological actions of the late twentieth century as the entrance to modern nursing care. Tele-nursing well-defined as the application of telecommunications and information technology to deliver nursing practice at a distance. It enhances quality of care, patient protection, and quick access to nursing care by overcoming geographical obstacles. The use of telephones, mobile phones, smart marketing system (SMS) and communication tech-neologies are part of tele-nursing (Donati, et al., 2019).

In COVID-19, the primary goal is to decrease the danger of infection transmission between nurses and patients. Tele-nursing appears to be a different and new opportunity in the COVID-19 Pandemic disaster to lessen hazard of infection, and expenditures. In addition, patients' education considered one of the greatest critical roles of the nurse (Kang, 2020). Thus, the application of tele-nursing education program helps improving nurses' compliance.

\section{Significance of Study}

Nurses play an extremely significant role locally and worldwide. They are a cornerstone for managing WHO's highest priority of comprehensive health coverage in adding to caring for patient's day in and day out. Nurses are worthy in handling a health disaster since they are an essential link between the patient and the remainder of the health care team. As the COVID-19 pandemic takes hold, nurses face a potential risk of infection (Aldohyan, et al., 2019; Khalid, et al., 2016). It was important to focus on nursing staff to protect them from COVID-19 infection.

\section{Operational Definitions}

Nurses' Compliance: The extent to which the nurses' behaviors accord through the instructions of the organization such infection constraint and inhibition behaviors would be cautiously observed.

Tele-nursing Education: using technology to increase nursing awareness and improve nursing care outcomes at a distance, may include synchronous, store and forward, and remote monitoring.

\section{Aim of the Study}

Evaluate the effect of tele-nursing education program on nurses' compliance with standard precautions during COVID-19 pandemic.

\section{Research Hypothesis}

The nurse's compliance with standard precautions will be improved after applying tele-nursing education program.

\section{Subjects and Methods}

Research Design

A Quasi-experimental research design was utilized in this study.

\section{Research Setting}

The present study was performed at Specialized Medical Hospital, Mansoura, Egypt

Subjects

218 Nurses were included, sample size has been determined utilizing the subsequent equation: $\mathrm{n}=$ $(\mathrm{z} 2 \times \mathrm{p} \times \mathrm{q}) / \mathrm{D} 2$ at CI $95 \%$. As occurrence of compliance equals non-occurrence $=\mathrm{p}=\mathrm{q}=0.50$,

Inclusion criteria: Nurses who are able to use communication technologies (computers, smartphones, email address) as a part of tele-nursing education program.

Exclusion criteria: supervisor nurses, nurses employed in administrative zones or in other nonclinical settings were excluded since they are more often than not less included in coordinate clinical care and subsequently, they are not portion of the target sample. In addition to nurses unable to communicate with program and complete online survey wherever by means of computers, smartphones, or tablets.

Tools for Data Collection

Two tools were used in data collection:

Tool I: A structured Nurses' Interviewing Questionnaire: Developed by the researchers consisting of 2 parts: Part 1; socio-demographic data including (age, gender, marital status, level of education, and clinical experience). Part 2; factors affecting nurses' compliance with slandered precautions (work area, previous training programs, availability of enough supplies, infection control policies and guidelines, hospital preparation for any infection outbreak, and nurses' knowledge about coronavirus). 
Tool II: The Compliance with standard precaution scale (CSPS): The CSPS is a self-administered questionnaire developed by Lam, 2014 based on the guidelines of the Standard Precautions of the World Health Organization and the Hong Kong Hospital Authority. It is composed of 20 items covering 5 levels of standard Precautions (using of protective devices, disposal of sharp instruments, disposal of waste, decontamination of spills \& used articles, and prevention of cross-infection).

Scoring system: $\mathrm{A}$ four-point Likert scale (zero $=$ never, one $=$ seldom, two $=$ sometimes and three $=$ always). Items 2, 4, 6, and 15 were negatively stated. Thus, scores need to be reversed before computations. A score of one was given to an "always" response, while zero for the other responses, giving a total possible range score of 0 to 20. Higher scores signify better compliance with SPs. Compliance rate: The total compliance rate refers to the average compliance with all 20 items in percentage. Currently, there is no cut-off value as determined by statistics. In general, it is optimal when compliance rate is $>90 \%$, satisfactory between $80 \%$ $89 \%$, suboptimal between $50 \%-79 \%$, and poor for < $49 \%$. The item compliance rate refers to the mean score of each item.

Content Validity: A panel of seven experts from Faculty of Nursing (Medical-Surgical and Critical Care Nursing Department) have checked the tools. Based on their opinions; modifications were made.

Test reliability of the tools was assessed using Cronbach's alpha test, showed high reliability of the tool as Tool II (CSPS): (0.747)

The Pilot Study was applied on 22 nurses $(10 \%)$ to test clarity and applicability of the tool and estimating the time needed to fill in the questionnaire. Nurses participated in the pilot study were excluded.

Field Work

The actual field work started from the beginning of May, 2020 to the end August 2020.The study comprised the following phases:

Preparatory phase: Developing structure questionnaire and the review of related literatures which carried out from the beginning of May, 2020 to the end of May 2020 (one-month duration).

Implementation Phase: The implementation phase started from the beginning of June, 2020 to end of August, 2020 (a period of 3 months), including pretest, program implementation, and post-test.

Pre \& Post -test: The survey was sent to nurses through the WhatsApp group via google drive link: https://forms.gle/uHno8KubaP5NtBSs6. For post-test; tool 2 was sent again on the WhatsApp group to re assess the nurses' compliance with standard precautions scale.
Intervention: The implementation of the tele-nursing education program was conducted through videos call, posters, power point presentation, and group discussions through the WhatsApp group and send copy via email address. The nurses were divided into groups, each group from (15-20 nurses), three sessions per one week followed by post-test survey:

First session: Included "overview" about covid-19; global and national situation, causative organism, mode of transmission, signs and symptoms, high-risk groups, and first precaution; strategies for infection prevention. Second precaution; early detection of infections signs, screening services, and providing emotional support to the isolated COVID-19.

Second session: Includes the third precaution: The use of PPE, the effectiveness of PPE; prompt access to sufficient supplies, appropriate hand hygiene, compliance and regular monitoring and feedback. Fourth precaution: Environmental cleaning "environmental cleaning and disinfection procedures" in the context of COVID-19.

Fifth precaution: Waste management during patients care with suspected or confirmed COVID-19.

Third session: six precaution: Prevention of needle stick injuries from other sharp instruments, cleaning used instruments, proper disposing of used needles and other sharp instruments. At the end of the session; open discussion for questions, recommendations, and focus on the nurses' responsibilities during covid-19 pandemic.

Evaluation Phase: Post-test was applied after implementation of the program immediately through link send on WhatsApp group.

\section{Ethical Considerations}

After explanation of purposes and nature of the study, an oral consent was obtained from all study nurses, maintaining anonymity and confidentiality of their data was assured. They were given the right to withdraw from the study at any time.

Statistical Analysis

Data were analyzed using IBM SPSS software package version 20.0. (Armonk, NY: IBM Corp) quantitative data were described using number and percent. The Kolmogorov-Smirnov test used to verify the normality of distribution of qualitative data described using range (minimum and maximum), mean, and standard deviation. Significance of the obtained results was judged at the $5 \%$ level. 


\section{Results}

Table (1): Socio Demographic Data of Studied Nurses $(n=218)$

\begin{tabular}{|c|c|c|c|}
\hline \multicolumn{2}{|r|}{ Variable } & No. & $\%$ \\
\hline \multicolumn{4}{|c|}{ Age (years) } \\
\hline$\bullet$ & $<25$ & 69 & 31.7 \\
\hline$\bullet$ & $25-<35$ & 144 & 66.0 \\
\hline$\bullet$ & $\geq 35$ & 5 & 2.3 \\
\hline \multicolumn{4}{|c|}{ Mean \pm SD: $28.22 \pm 5.81$} \\
\hline \multicolumn{4}{|c|}{ Gender } \\
\hline$\bullet$ & Male & 30 & 13.8 \\
\hline$\bullet$ & Female & 188 & 86.2 \\
\hline \multicolumn{4}{|c|}{ Marital Status } \\
\hline$\bullet$ & Single & 55 & 25.2 \\
\hline$\bullet$ & Married & 161 & 73.9 \\
\hline$\bullet$ & Widowed & 2 & 0.9 \\
\hline \multicolumn{4}{|c|}{ Level of Education } \\
\hline$\bullet$ & Diploma Schools & 6 & 2.8 \\
\hline$\bullet$ & Associate Programs & 83 & 38.1 \\
\hline$\bullet$ & Bachelor Degree & 94 & 43.1 \\
\hline$\bullet$ & Master's Degree & 21 & 9.6 \\
\hline$\bullet$ & PHD Degree & 14 & 6.4 \\
\hline \multicolumn{4}{|c|}{ Clinical Experience (years) } \\
\hline$\bullet$ & $<3$ years & 58 & 26.6 \\
\hline$\bullet$ & $3-$ & 94 & 43.1 \\
\hline$\bullet$ & $8-$ & 40 & 18.3 \\
\hline$\bullet$ & $\geq 13$ years & 26 & 11.9 \\
\hline
\end{tabular}




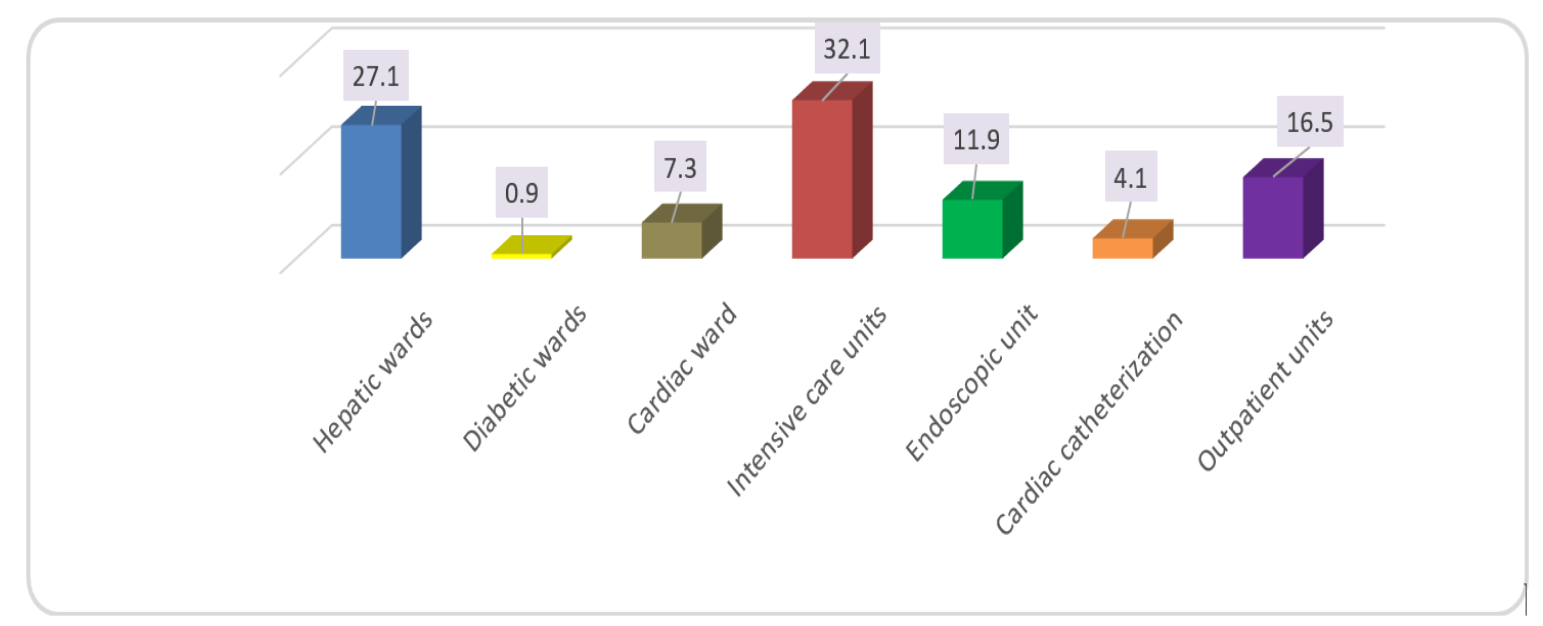

Figure (1): Distribution of Nursing Staff according to Working Areas

Table (2): Factors affecting Standard Precautions Application

\begin{tabular}{|c|c|c|c|c|}
\hline \multirow{2}{*}{ Variable } & \multicolumn{2}{c|}{ Yes } & \multicolumn{2}{c|}{ No } \\
\cline { 2 - 5 } & No. & No. & \% \\
\hline $\begin{array}{l}\text { 1. Previous training program about standard precautions. } \\
\text { 2. Availability of enough supplies to apply standard } \\
\text { precautions }\end{array}$ & 125 & 57.3 & 93 & 42.7 \\
\hline $\begin{array}{l}\text { 3. Infection control policies and guidelines in work area } \\
\text { 4. The hospital is prepared for any infection outbreak }\end{array}$ & 151 & 69.3 & 67 & 30.7 \\
\hline 5. Do you have enough knowledge about coronavirus? & 212 & 97.2 & 67 & 44.5 \\
\hline
\end{tabular}


Table (3): Comparison between Standards Precautions Scores of the Studied Nurses in Pre \& Post Telenursing Program $(\mathrm{n}=218)$

\begin{tabular}{|c|c|c|c|c|c|c|c|c|c|c|c|c|}
\hline \multirow[t]{3}{*}{ No. } & \multirow[t]{3}{*}{ Variable } & \multicolumn{5}{|c|}{ Pretest } & \multicolumn{5}{|c|}{ Posttest } & \multirow[t]{3}{*}{ p-value } \\
\hline & & \multicolumn{4}{|c|}{ Frequency of Endorsement, \% } & \multirow{2}{*}{$\begin{array}{l}\text { Compliance } \\
\text { Rate \% }\end{array}$} & \multicolumn{4}{|c|}{ Frequency of Endorsement, \% } & \multirow{2}{*}{\begin{tabular}{|} 
Complianc \\
e \\
Rate $\%$
\end{tabular}} & \\
\hline & & Never & Seldo & Sometimes & Always & & Neve & Seldo & $\begin{array}{r}\text { Some- } \\
\text { times }\end{array}$ & Alway & & \\
\hline 1 & I wash my hands between patient contacts & 23.4 & 26.6 & 3.2 & 46.8 & 46.8 & 0.9 & 5.0 & 4.6 & 89.4 & 89.4 & $<0.001^{*}$ \\
\hline 2 & I only use water for hand washing & 50.9 & 8.3 & 28.9 & 11.9 & 50.9 & 84.4 & 7.3 & 7.8 & 0.5 & 84.4 & $<0.001 *$ \\
\hline 3 & $\begin{array}{l}\text { I use alcohol hand rubs as an alternative if my hands are not } \\
\text { visibly soiled }\end{array}$ & 5.0 & 5.0 & 33.0 & 56.9 & 56.9 & 6.4 & 2.3 & 16.5 & 74.8 & 74.8 & $<0.001 *$ \\
\hline 4 & I recap used needles after giving an injection & 63.8 & 11.0 & 4.6 & 20.6 & 63.8 & 84.4 & 10.1 & 3.7 & 1.8 & 84.4 & $<0.001^{*}$ \\
\hline 5 & I put used sharp articles into sharps boxes & 0.5 & 22.5 & 16.5 & 60.6 & 60.6 & 0.0 & 1.4 & 2.8 & 95.9 & 95.9 & $<0.001^{*}$ \\
\hline 6 & The sharps box is only disposed when it is full & 53.2 & 6.9 & 17.0 & 22.9 & 53.2 & 75.7 & 12.8 & 8.7 & 2.8 & 75.7 & $<0.001^{*}$ \\
\hline 7 & I remove PPE in a designated area & 5.5 & 7.3 & 31.2 & 56.0 & 56.0 & 1.4 & 3.7 & 11.5 & 83.5 & 83.5 & $<0.001 *$ \\
\hline 8 & $\begin{array}{l}\text { I take a shower in case of extensive splashing even after I } \\
\text { have put on PPE }\end{array}$ & 11.5 & 16.5 & 26.1 & 45.9 & 45.9 & 0.0 & 0.0 & 11.5 & 88.5 & 88.5 & $<0.001 *$ \\
\hline 9 & $\begin{array}{l}\text { I cover my wound (s) or lesion (s) with waterproof dressing } \\
\text { before patient contacts }\end{array}$ & 0.0 & 0.0 & 19.3 & 80.7 & 80.7 & 0.0 & 0.0 & 1.4 & 98.6 & 98.6 & $<0.001 *$ \\
\hline 10 & $\begin{array}{l}\text { I wear gloves when I am exposed to body fluids, blood } \\
\text { products, and any excretion of patients }\end{array}$ & 0.0 & 0.5 & 28.4 & 71.1 & 71.1 & 0.0 & 0.9 & 4.6 & 94.5 & 94.5 & $<0.001^{*}$ \\
\hline 11 & I change gloves between each patient contact & 0.5 & 10.6 & 33.5 & 55.5 & 55.5 & 1.4 & 1.8 & 6.9 & 89.9 & 89.9 & $<0.001 *$ \\
\hline 12 & $\begin{array}{l}\text { I decontaminate my hands immediately after removal of } \\
\text { gloves }\end{array}$ & 1.8 & 2.8 & 34.9 & 60.6 & 60.6 & 2.3 & 2.8 & 5.5 & 89.4 & 89.4 & $<0.001 *$ \\
\hline 13 & $\begin{array}{l}\text { I wear a surgical mask alone or in combination with } \\
\text { goggles, face shield, and apron whenever there is a } \\
\text { possibility of a splash or splatter }\end{array}$ & 3.2 & 0.9 & 29.8 & 66.1 & 66.1 & 0.5 & 0.5 & 21.6 & 77.5 & 77.5 & $<0.001 *$ \\
\hline 14 & My mouth and nose are covered when I wear a mask & 0.0 & 0.0 & 11.5 & 88.5 & 88.5 & 1.4 & 1.8 & 1.8 & 95.0 & 95.0 & $0.011^{*}$ \\
\hline 15 & I reuse mask or disposable PPE & 67.4 & 6.4 & 21.1 & 5.0 & 67.4 & 83.5 & 13.8 & 2.8 & 0.0 & 83.5 & $<0.001 *$ \\
\hline 16 & $\begin{array}{l}\text { I wear a gown or apron when exposed to blood, body fluids, } \\
\text { or any patient excretions }\end{array}$ & 2.3 & 4.6 & 22.9 & 70.2 & 70.2 & 0.0 & 1.4 & 7.8 & 90.8 & 90.8 & $<0.001 *$ \\
\hline 17 & $\begin{array}{l}\text { Waste contaminated with blood, body fluids, secretion, and } \\
\text { excretion are placed in red plastic bags irrespective of } \\
\text { patient's infective status }\end{array}$ & 0.5 & 0.5 & 30.3 & 68.8 & 68.8 & 0.9 & 2.3 & 6.9 & 89.9 & 89.9 & $<0.001 *$ \\
\hline 18 & I decontaminate surfaces and equipment after use & 0.0 & 0.0 & 22.5 & 77.5 & 77.5 & 0.0 & 0.0 & 7.3 & 92.7 & 92.7 & $<0.001 *$ \\
\hline 19 & $\begin{array}{l}\text { I wear gloves to decontaminate used equipment with visible } \\
\text { soils }\end{array}$ & 0.0 & 0.0 & 5.5 & 94.5 & 94.5 & 0.0 & 0.0 & 0.9 & 99.1 & 99.1 & $0.008^{*}$ \\
\hline 20 & $\begin{array}{l}\text { I clean up spillage of blood or other body fluid immediately } \\
\text { with disinfectants }\end{array}$ & 6.0 & 0.0 & 4.6 & 89.4 & 89.4 & 0.0 & 1.8 & 0.9 & 97.2 & 97.2 & $<0.001 *$ \\
\hline
\end{tabular}

$p$ : $p$ value for comparing between pre and post

*: Statistically significant at $p \leq 0.05$ 
Table (4): Comparison between Mean Scores of Standards Precautions Scale in Pre \& Post Telenursing Program.

\begin{tabular}{|c|c|c|c|c|}
\hline \multirow{2}{*}{ Variable } & Pre & Post & \multirow{2}{*}{$\mathbf{T}$} & \multirow{2}{*}{ p-value } \\
\hline & Mean \pm SD. & Mean \pm SD. & & \\
\hline \multicolumn{5}{|l|}{ Use of protective device: } \\
\hline Total score & $4.19 \pm 1.31$ & $5.25 \pm 0.94$ & \multirow{2}{*}{$15.022^{*}$} & \multirow{2}{*}{$<0.001^{*}$} \\
\hline$\%$ score & $69.88 \pm 21.82$ & $87.46 \pm 15.62$ & & \\
\hline \multicolumn{5}{|l|}{ Disposal of sharps } \\
\hline Total score & $1.78 \pm 0.86$ & $2.56 \pm 0.64$ & \multirow{2}{*}{$15.268^{*}$} & \multirow{2}{*}{$<0.001^{*}$} \\
\hline$\%$ score & $59.17 \pm 28.80$ & $85.32 \pm 21.43$ & & \\
\hline \multicolumn{5}{|l|}{ Disposal of waste } \\
\hline Total score & $0.69 \pm 0.46$ & $0.90 \pm 0.30$ & \multirow{2}{*}{$7.416^{*}$} & \multirow{2}{*}{$<0.001^{*}$} \\
\hline$\%$ score & $68.81 \pm 46.43$ & $89.91 \pm 30.19$ & & \\
\hline \multicolumn{5}{|c|}{ Decontamination of spills and used article: } \\
\hline Total score & $2.61 \pm 0.64$ & $2.89 \pm 0.36$ & \multirow{2}{*}{$7.513^{*}$} & \multirow{2}{*}{$<0.001^{*}$} \\
\hline$\%$ score & $87.16 \pm 21.42$ & $96.33 \pm 11.84$ & & \\
\hline \multicolumn{5}{|c|}{$\begin{array}{l}\text { Prevention of cross infection from person to } \\
\text { person }\end{array}$} \\
\hline Total score & $3.97 \pm 1.51$ & $6.15 \pm 1.0$ & \multirow{2}{*}{$20.862^{*}$} & \multirow{2}{*}{$<0.001^{*}$} \\
\hline$\%$ score & $56.75 \pm 21.51$ & $87.88 \pm 14.25$ & & \\
\hline \multicolumn{5}{|l|}{ Overall } \\
\hline Total score & $13.24 \pm 3.36$ & $66.22 \pm 16.78$ & \multirow{2}{*}{$24.691^{*}$} & \multirow{2}{*}{$<0.001^{*}$} \\
\hline$\%$ score & $17.75 \pm 2.38$ & $88.74 \pm 11.90$ & & \\
\hline
\end{tabular}

Table (1): Reveals that $86.2 \%$ of the studied nurses were females, $41.7 \%$ of them were in age group 26 30 with the mean age of 28.22 years, $73.9 \%$ of nurses were married. As regards to level of education, 43.1 had Bachelor Nursing degree. $43.1 \%$ of nurses had 3 to 8 years of clinical experience while $11.9 \%$ of them had more than 13 years' experience.

Figure (1): Shows that $32.1 \%, 27.1 \%, \& 16 \%$ of the studied nurses were working in intensive care units, hepatic wards, and outpatient clinics respectively.

Table (2): Reveals that $45.4 \%$ of respondents received training program on standard precautions, 57.3 of nurses reported that there were enough supplies to apply standard precautions. $69.3 \%$ of them had infection control policies and guidelines in their unit, $55.5 \%$ of them reported that their hospitals are prepared for any infection outbreak. Concerning their knowledge about coronavirus; $97.2 \%$ of the nurses had enough knowledge about coronavirus

Table (3): Shows the scores for each item of the CSPS. There was a highly statistically significant difference in all items of compliance with standard precautions scale between pretest and posttest with $\mathrm{p}$ value $<0.001$.

Table (4): Shows a highly significant statistical difference in mean scores of compliance standards precautions scale between the pre \& post-test, with $\mathrm{p}$ value $<0.001$.

\section{Discussion}

Tele-nursing is one such proposed means of improving health care globally Reierson, et al., 2015. Little researches focus on its importance. GallagherLepak et al., 2009. The use of tele-nursing technology to deliver educational program from a distance has proven to be an effective way of overcoming certain barriers that taken during Covid19 pandemic.

Lam (2014) informed that Since infection control practice is continuously highlighted in clinical setting, face-to-face interview will not obtain a reliable response owing to possible social desirability bias. It is suggested to practice self-administrated technique (online or returned the questionnaire with sealed envelope) for data collection. Confidentiality would be permanently emphasized. So, Telenursing seems to be atypical and new opportunity in the COVID-19 pandemic disaster to apply educational program for nurses about compliance with standard precautions. 
Regarding sociodemographic data; the results revealed that about two thirds of studied nurses were in adult age from (25- >35), most of them were females, and near three quarters of them were married. Regarding the level of education and clinical experience, it was noticed that about one half of the nurses were highly educated and having from three to eight years of experience. These findings go in the same line with the results of Beyamo, et al., 2019; revealed that more than half of their subjects in the same age group with our study, more than two thirds were females, and more than half of them had 2 to 5 year service experiences. However these findings in accordance with the results of Labrague, et al., 2012 who found that more than majority of nurses were within the age bracket of 21 to 23 years old with mean age of 21.5 years, and the majority of them were single. Donati, et al., 2019 found that the majority of the sample was female and their ages ranged from 26 to 35 years. About half of the sample completed one or more first-level professional master program, and minority of participants had a master's degree or a higher education level. More than half of participants had between 3 and 10 years of job experience.

From the researcher point of view, the age group between from $(25->35)$, years old represents working-age in clinical setting as intensive care units, hepatic wards, cardiac wards who provide direct care to the patients and nurses older than 35 years old distributed in outpatients clinics and other nonclinical settings. Most of nurses were females because the overall percent of female nurses in hospital is more than male, therefore as of their age group and their sex as female near three quarters of them were married.

Regarding distribution of nurses according to clinical settings, the outcomes of the existing study show that about two thirds of the studied nurses were working at intensive care units and hepatic wards while only less than one fourth working on outpatient clinic. This finding in contrast with the results of Donati, et al., 2019 who described that more than half of nurses worked in adult medical-surgical while minority of them were worked in intensive care unit. This can be explained by these clinical setting requires more efforts and responsibilities which is suitable to their age group.

Regarding the factors affecting compliance with standard precautions, the results of the current study reveal that about one-half of the studied nurses did not receive training programs about standard precautions. These findings in accordance with the results of Alshammari, et al; 2018; a study carried out in Saudi Arabia had reported that more than three quarters of the study subjects did not receive training about standard precautions. This may be due to shortage of staff, lack of time and increase flow rate of the patients with increase in numbers Covid 19 cases. About two thirds of the nurses mentioned that there were enough supplies to apply standard precautions. From the researcher point of view, this is a national direction to maintain the health care providers away from infection, prevent transmission of infection among the patients and reduce the cases with Covid 19

As regards to infection control policies and guidelines in the unit about three quarters of nurses have infection control policies and guidelines in their unit while less than half of nurses encountered outbreak before and their hospital is prepared for any infection outbreak. These findings is supported by Fernandez, et al., 2020 who reported that occupational and organizational readiness to deal with the widespread affected significantly on frontline nursing staff one of the major variables that affected nurses' capacity to manage the requesting workload amid the pandemic were staffing deficiencies and supplies.

Concerning the knowledge about coronavirus, almost all of nurses had enough knowledge about coronavirus. These finding was in the same line with Wahed, et.al, (2020), who found that the most of respondent's level of the knowledge about COVID-19 was high. This comes in accordance with studies conducted in China, Vietnam, and Pakistan (Zhou, et.al (2020), Giao, et.al, (2020), Saqlain, et.al, (2020). Similarly, a Ugandan study had reported about three fourth of their respondents had sufficient level of knowledge (Olum, et.al., (2020), also in an Iranian study it was found that about all of respondents had excellent knowledge level regarding the disease modes of transmission but regarding the disease symptoms more than most of the nurses had sufficient knowledge (Maleki,et.al., (2020). On the other hand in a study from the United Arab Emirates, poor knowledge about the disease transmission, and the symptom was found in a significant proportion of HCWs From the researcher point of view, Covid 19 pandemic is critical situation that required from each health care providers armed with required knowledge that protect them and community from infection.

The main objective of the present study was to evaluate the effect of telenursing education program on nurse's compliance with standard precaution during pandemic covid- 19. The results of this study displayed a highly significant improvement of nurses' compliance with standard precautions scores after implementation of tele-nursing education program, which reflects the effectiveness of the program. These results in accordance with Gomarverdi, et al., 2019, who reported that the multi-component educational interventions had demonstrated initial effectiveness in 
enhancing ICU nurses' adherence to the SPs guidelines, and the intervention is a promising approach for designing effective continuing education initiatives aimed to improve nurses' practice. Xiong, et al., 2017 also revealed that a mixed media intervention for nursing students had a significant effect on their clinical training and compliance with the intervention. These finding is in disagreement with Luo, et al. 2010). where they observed that the use of protective items such as eye shields, masks, and quarantine clothes among Chinese nurses had the lowest compliance. From the researcher point of view, the dangers surrounding the nurses have led them to focus and increase their interest in knowing how to prevent and control infection through implementation of standards precautions and compliance

\section{Conclusion}

The study results concluded that; application of the tele-nursing education program has improved the nurses' compliance scores with standard precaution scale, In addition; tele-nursing appears to be interesting for nurses that can be used in the care of community-dwelling subjects.

\section{Recommendations}

Based on the current study results, the following recommendations are suggested:

- Written universal precautions guidelines for infection control should be available and updated periodically.

- Obligatory seminars/workshops on standard precautions should be continuously structured by hospital managers to increase awareness and practice of HCWs

\section{References}

- Aldohyan, N., Al-Rawashdeh, M. Sakr, S. Alfarhan, A. \& Salam. M (2019): The perceived effectiveness of MERS-CoV educational programs and knowledge transfer among primary healthcare workers: a cross-sectional survey. 2019. 19 (1): p. 273.

- Alshammari. F, Cruz,P. J, Alquwez. N, JoAlmazan. J, Alsolami. F, Tork. H, Alabdulaziz. H, \& Felemban. M.E, (2018): Compliance with standard precautions during clinical training of nursing students in Saudi Arabia: A multi-university study. 2018. 12(11): p. 937-945.

- Beyamo, A., T. Dodicho, \& W.J.B.h.s.r. Facha, (2019): Compliance with standard precaution practices and associated factors among health care workers in Dawuro Zone, South West Ethiopia, cross sectional study. 2019. 19 (1): p. 381.
- Rio, D. (2020): Malani, COVID-19-new insights on a rapidly changing epidemic. Jama, 2020. 323(14): p. 1339-1340.

- Donati, D., Biagioli, V., Cianfrocca, C., De Marinis, M.G., Tartaglini, D, (2019): Compliance with standard precautions among clinical nurses: Validity and reliability of the Italian version of the Compliance with Standard Precautions Scale (CSPS-It). International Journal of Environmental Research and Public Health, 2019. 16 (1): p. 121.

- Fernandez, R. Lord, H Halcomb, E., Moxham, L. Middleton, R. Alananzeh, R. \& Ellwood, L. (2020): Implications for COVID-19: a systematic review of nurses' experiences of working in acute care hospital settings during a respiratory pandemic. 2020: p. 103637.

- Gallagher-Lepak, S., Scheibel, P. \& Gibson, I. (2009): Integrating telehealth in nursing curricula: Can you hear me now. 2009. 13 (2): p. 2.

- Huynh, G. Nguyen, T. Tran, V.KH. Vo, K.N. Vo, V.T. Le An Pham, (2020): Knowledge and attitude toward COVID-19 among healthcare workers at District 2 Hospital, Ho Chi Minh City. Asian Pacific J Trop Med. 2020; 13:3-5. doi: 10.4103/1995-7645.280396.

- Gomarverdi, SH. Khatiban, M. Bikmoradi, M. \& Soltanian, A.R. (2019): Effects of a multicomponent educational intervention on nurses' knowledge and adherence to standard precautions in intensive care units. 2019. 20(2): p. 83-90.

- Jin, X., (2019): Epidemiological, clinical and virological characteristics of 74 cases of coronavirus-infected disease (COVID-19) with gastrointestinal symptoms. 2020. 69(6): p. 10021009.

- Kang, Y. (2020): Critical Care for Patients with Severe Covid-19 in Sichuan Province, China: Provincial Cohort Study. 2020.

- Khalid, I MD, FCCP, Tabindeh J. Khalid, MD, Mohammed R. Qabajah, RN, Aletta G. Barnard, RN Ismael A. \& Qushmaq, MD, (2016): Healthcare workers emotions, perceived stressors and coping strategies during a MERS-CoV outbreak. 2016.14 (1): p. 7-14.

- Labrague, L.J., Rosales, R.A. \& Tizon, M.M. (2012): Knowledge of and compliance with standard precautions among student nurses. 2012. 1 (2): p. 84-97.

- Lam, S. (2014): Validation and cross-cultural pilot testing of compliance with standard precautions scale: self-administered instrument for clinical nurses. 2014. 35 (5): p. 547-55.

- Luo, Y., He, G-P., Zhou, J.-W., \& Luo, Y. (2010): Factors impacting compliance with standard precaution in nursing, china. International Journal 
of Infectious Diseases, 14(12), e1106-e1114. http://dx.doi.org/10.1016/j.ijid.2009.03.037.

- Olum, R. Chekwech, G. Wekha, G. Nassozi, D.R. \& Bongomin, F. (2020): Coronavirus disease2019: Knowledge, attitude, and practices of health care workers at Makerere University Teaching Hospitals Uganda. Frontiers in Public Health. 2020; 8:181. doi: 10.3389/fpubh.2020.00181.

- Organization, W.H. (2020): Coronavirus disease ( COVID-19): situation report, 165. 2020.

- Organization, W.H. (2020): Modes of transmission of virus causing COVID-19: implications for IPC precaution recommendations: scientific brief, 27 March 2020. 2020, World Health Organization.

- Organization, W.H. (2020): Transmission of SARS-CoV-2: implications for infection prevention precautions: scientific brief, 09 July 2020. World Health Organization.

- Purabdollah, M. \& Ghasempour, M. (2020): Tele-Nursing New Opportunity for Nursing Care in COVID-19 Pandemic Crisis. Iranian Journal of Public Health, 2020. 49: p. 130-131.

- Reierson, I.Å., \& Solli, H. (2015): Bjørk, Nursing students' perspectives on telenursing in patient care after simulation. 2015. 11(4): p. 244-250.

- Rios-González, C.M., (2020): Knowledge, attitudes and practices towards COVID-19 in Paraguayans during outbreaks: a quick online survey.

https://doi.org/10.1590/SciELOPreprints.149

- Rothan, H.A. \& Byrareddy, S.N, (2020): The epidemiology and pathogenesis of coronavirus disease (COVID-19) outbreak. Journal of autoimmunity, 2020: p. 102433.

- Saba, A.I. \& Elsheikh, A.H. (2020): Forecasting the prevalence of COVID-19 outbreak in Egypt using nonlinear autoregressive artificial neural networks. Process Safety and Environmental Protection, 2020.

- Hendy A, Abozeid, A, Sallam G, AbdelFattah ,A.H, \& Reshia F, (2020): Predictive factors affecting stress among nurses providing care at COVID-19 isolation hospitals at Egypt. Nursing Open. 2020;00:1-8. https://doi.org/10.1002/nop2.652

- Saqlain M. Munir M.M ,Rehman S.U, Gulzar A, Naz S. Ahmed Z, Tahir A.H, \& Mashhoo, M. (2020): Knowledge, attitude, practice and perceived barriers among healthcare professionals regarding
COVID-19: A Cross-sectional survey from Pakistan. medRxiv. 2020.

- Abdel Wahed, Y.F. Hefzy, M.H. Ahmed, I.A. \& Hamed, S.H. (2020): Community Health. 2020 Jul 7 : 1-10. doi: 10.1007/s10900-020-00882-0

- Wang C, Horby PW, Hayden FG, \& Gao GF, (2020): A novel coronavirus outbreak of global health concern. Lancet [Internet]. 2020 Jan [cited 2020 Feb 10]; Available from: https://linkinghub.elsevier.com/retrieve/pii/S014067 $\underline{3620301859}$

- Xiong. P. MSN, Zhang, R. \& RNb Brian, R. (2017): Effects of a mixed media education intervention program on increasing knowledge, attitude, and compliance with standard precautions among nursing students: A randomized controlled trial. 45 (4): p. 389-395.

- Zhou M, Tang F, \& Wang Y, (2020): Knowledge, attitude and practice regarding COVID-19 among health care workers in Henan, China. Journal of Hospital Infection. 2020 doi: 10.1016/j.jhin.2020.04.012. 